\title{
The Analytical Model of Biomass Combustion
}

\author{
Alexander Backa ${ }^{1, *}$, Radovan Nosek ${ }^{1}$, and Alexander Čaja ${ }^{1}$ \\ ${ }^{1}$ Department of Power Engineering, Faculty of Mechanical Engineering, University of Žilina, \\ Univerzitná 1, 01026 Žilina, Slovakia
}

\begin{abstract}
The standard detection of the emission and power parameters of the combustion process can be time and money consuming due to the performance of experimental measurements with the necessary measuring instruments. Alternatives to describe the combustion process are mathematical models. Their variability is high and therefore, depending on the need for use, an analytical mathematical model was chosen. Among the computationally faster and less time-consuming models is the analytical model, which can not only describe some parameters of the combustion process (power, emissions and others) but also predict the parameters of the combustion process according to the selected input values. This work is focused on the prediction of selected emission parameters through an analytical model for $100 \%$ straw and $100 \%$ wood pellets.
\end{abstract}

\section{Introduction}

At present, humanity is increasingly reaching for alternative energy sources, because the traditional ones will not always be sufficient and many available sources could not be used effectively due to insufficient levels of technological sophistication. The combustion process is a relatively demanding process, which can be partially described using various models (mathematical, physical, etc.). Thanks to the models, it is possible not only to characterize the given event but also to predict various parameters of the combustion process. The results thus obtained, depending on the accuracy and complexity of a particular model, can be used in the design of combustion plants or to describe a particular combustion state. More demanding models require a larger amount of input data and also their calculation methodology tends to be more complex. Computationally simpler models with less data input usually do not achieve such accuracy. However, the accuracy of the calculation depends not only on the model but also on appropriately selected input parameters. These parameters must be correctly identified, while with a high number of variables it is possible to neglect those that have a minimal impact on the result, but it also depends on the required quality of the calculation [1].

This article describes an analytical model, which is one of the computationally simpler mathematical models. Its advantage is the fast calculation, as well as a small amount of required input data. This model is suitable where indicative data are sufficient. If simulations are needed, other types of models are more suitable, such as e.g. numerical model using CFD simulation [2].

\footnotetext{
*Corresponding author: alexander.backa@fstroj.uniza.sk
} 
Based on simple mathematical - chemical equations, an analytical model was created, which is used to predict the individual quantities studied. The design of the model was developed from the stoichiometry of only perfect or only imperfect combustion, which means that it is idealized and does not describe a situation where the opposite phenomenon occurs.

The proposed model consists of a set of relationships describing the individual quantities occurring in the description of the fuel (calorific value of the fuel) or in the description of the combustion process (amount of wet flue gas and generated $\mathrm{CO}, \mathrm{SO}_{2}$ and $\mathrm{N}_{2}$ emissions in the flue gas). In this way, it is possible to create a set of several examined parameters, but not all combustion parameters can be expressed analytically.

\section{Materials and methods}

To determine these parameters, the data of available measurements for $100 \%$ straw and $100 \%$ wood sawdust (pellets) (Figure 1) performed using a CHN628 series analyser (Figure 2) were used. This equipment performs chemical analysis of fuel - hydrogen, nitrogen and carbon. The compilation of the computational analytical module was realized in the Excel environment.

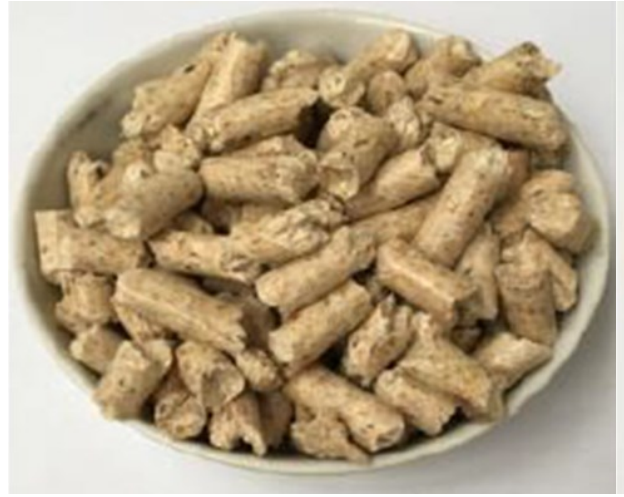

(a)

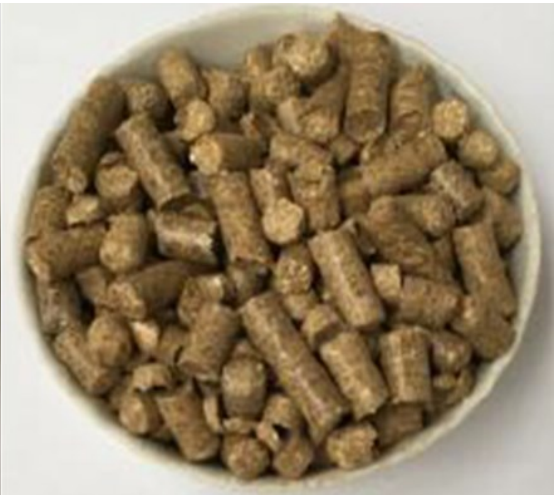

(b)

Fig. 1. Samples: (a) $100 \%$ wood pellets, (b) $100 \%$ straw pellets.

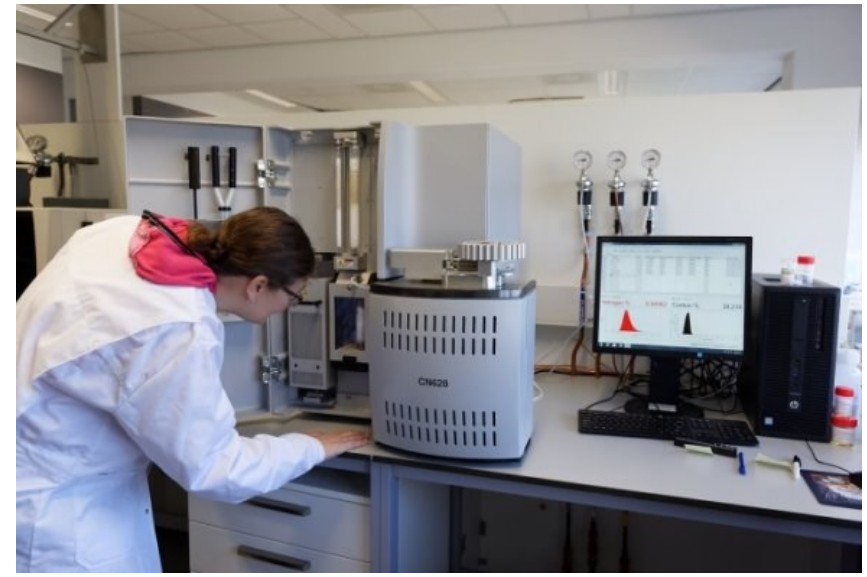

Fig. 2. CHN628 analyser [3]. 


\section{Experimental research}

The analytical calculation was performed to determine the calorific value of the fuel as well as to determine the total amount of humid air supplied with partial calculations of the emission components. The basic relations for the calculation of the selected parameters are based on the stoichiometry of combustion [4].

\subsection{Calculation of fuel calorific value}

One of the basic empirical equations can be used to determine the calorific value of the fuel, and these equations differ in individual coefficients. When determining the calorific value, the calculation of the combustion heat less the heat of vaporization of the water is used. A corrected Dulong formula was used for this calculation [5].

$$
Q_{\mathrm{i}}=33.91 * C^{r}+121.42 * H^{r}-15.18 * O^{r}+10.47 * S^{r}-2.45 * W^{r}\left(k^{\prime} . \mathrm{kg}^{-1}\right)
$$

where:

$Q^{r}$ is the calorific value in $\left[\mathrm{kJ} \cdot \mathrm{kg}^{-1}\right]$,

$C^{r}$ is the amount of carbon in the sample [\% wt],

$H^{r}$ is the amount of hydrogen in the sample [\% wt],

$O^{r}$ is the amount of oxygen in the sample [\% wt],

$S^{r}$ is the amount of sulfur in the sample [\% wt],

$W^{r}$ is the bound moisture in the sample v [\% wt].

From the chemical analysis of $100 \%$ straw pellet fuel:

$C^{r}=44.64 \% \mathrm{wt}$

$H^{r}=5.77 \% \mathrm{wt}$;

$N^{r}=4.26 \% \mathrm{wt} ;$

$O^{r}=33.35 \% \mathrm{wt}$;

$S^{r}=0.15 \% \mathrm{wt}$

$W^{r}=6.87 \%$ wt.

From chemical analysis of fuel $100 \%$ wood pellets:

$C^{r}=48.78 \% \mathrm{wt}$;

$H^{r}=6.31 \% \mathrm{wt}$

$N^{r}=0.13 \% \mathrm{wt}$

$\mathrm{O}^{\mathrm{r}}=41.32 \% \mathrm{wt}$

$S^{r}=0.014 \% \mathrm{wt}$

$W^{r}=3.86 \% \mathrm{wt}$.

Determination of fuel calorific value from measured values for $100 \%$ straw pellets from equation 1 :

$$
\begin{gathered}
Q_{i . s}=33.91 * 0.4464+121.42 * 0.0577-15.18 * 0.3335+10.47 * 0.0015-2.45 * 0.0687= \\
=16.928 \mathbf{k J}^{.} \mathbf{k g}^{-1}
\end{gathered}
$$

Determination of fuel calorific value from measured values for $100 \%$ wood pellets from equation 1 :

$$
\begin{gathered}
Q_{\text {i.d }}=33.91 * 0.4878+121.42 * 0.0631-15.18 * 0.4132+10.47 * 0.00014-2.45 * 0.0386= \\
=17.893 \mathbf{k J . k g}^{-1}
\end{gathered}
$$




\subsection{Determination of the total actual volume of wet flue gas.}

To determine the total actual volume of wet flue gas, it is necessary to calculate the individual sub-parameters that affect the selected quantity - the total volume of wet flue gas.

The actual wet flue gas volume is expressed in terms of the stoichiometric amount of wet flue gas $(V s p v)$, the stoichiometric amount of humid air $(V v z v)$ and the excess air.

$$
V_{\mathrm{spnv}}=V_{s p v}+(\lambda-1) * V v z v\left(m_{n}{ }^{3} * \mathrm{~kg}^{-1}\right)
$$

Under real conditions, the relationship would be adjusted by conversion through the real measured air pressure in $\mathrm{Pa}\left(p_{v z}\right)$ and flue gas temperature during the operating state of the boiler in $\mathrm{K}\left(t_{s p}\right)$.

$$
V_{\text {spnv.real }}=V_{\text {spnv }}+\left(273.15+t_{s p}\right) / 273.15 * 101325 / p_{v z}\left(m_{n}{ }^{3} k^{-1}\right)
$$

The stoichiometric amount of wet flue gas is expressed as the sum of the stoichiometric amount of dry flue gas $\left(V_{s p s}\right)$ and the volume of water vapour in the stoichiometric amount of wet flue gas $\left(V_{H 2 O}, v s\right)$ :

$$
V_{s p v}=V_{s p s}+V_{H 2 O . v s}\left(m_{n}^{3 *} k g^{-1}\right)
$$

Subsequently, for the overall calculation, it is necessary to determine the stoichiometric amount of dry air, which is expressed as the sum of the individual components produced from combustion:

$$
V_{\mathrm{sps}}=V_{\mathrm{CO} 2}+V_{\mathrm{SO} 2}+V_{\mathrm{N} 2}+V_{\mathrm{Ar}}\left(m_{n}{ }^{3} \mathrm{~kg}^{-1}\right)
$$

Of which $V_{A r}$ is given in equation 5, other parameters are calculated in separate subchapters:

$$
V_{\mathrm{Ar}}=0.0092 * V_{v z v}\left(m_{n}{ }^{3 *} \mathrm{~kg}^{-1}\right)
$$

The following applies to the volume of water vapour in the stoichiometric amount of wet flue gas:

$$
V_{H 2 O . v s}=44.82 / 4.032 \mathrm{H}^{r}+22.41 / 18.016 \mathrm{~W}^{r}+V_{H 2 O}\left(m_{n}{ }^{3 *} \mathrm{~kg}^{-1}\right)
$$

The amount of water vapor in humid air is calculated as the difference between the stoichiometric amount of humid air $\left(V_{v z v}\right)$ and a stoichiometric amount of dry air $\left(V_{v z s}\right)$ :

$$
V_{\mathrm{H} 2 \mathrm{O}}=V_{v z v}-V_{v z s}\left(m_{n}{ }^{3} * \mathrm{~kg}^{-1}\right)
$$

The calculation of the amount of dry air $(V v z s)$ is given in equation 12.1, the calculation of the humid air $\left(V_{v z v}\right)$ is performed using the product of the water vapour content $\left(x_{v p}\right)$ and the dry air. $\left(V_{v z s}\right)$.

$$
V_{\mathrm{vzv}}=\mathrm{x}_{v p} * V_{v z s}\left(m_{n}{ }^{3 *} \mathrm{~kg}^{-1}\right)
$$

The proportion of water vapour is calculated by means of the relative humidity of the air $(\varphi)$ and air parameters $\left(\mathrm{p}_{\mathrm{p}}\right.$ " - partial pressure of saturated steam $(\mathrm{Pa}), \mathrm{p}_{\mathrm{a}}$ - atmospheric pressure $(\mathrm{Pa}))$ :

$$
\mathrm{x}_{v p}=1+\varphi / 100 * \mathrm{p}_{\mathrm{p}}{ }^{\prime} /\left(\mathrm{p}_{\mathrm{a}}-\varphi / 100 * \mathrm{p}_{\mathrm{p}}{ }^{\prime}\right)\left(m_{n}{ }^{3 *} \mathrm{~kg}^{-1}\right)
$$


3.2.1 Calculation of the actual volume of wet flue gas for $100 \%$ straw pellets

$$
\begin{aligned}
& x_{v p}=1+70 / 100 * 3165 /(98050-70 / 100 * 3165)=1.023 m_{n}{ }^{3} \mathrm{~kg}^{-1} \quad \text { (from equation 9) } \\
& V_{\mathrm{vzv}}=1.023 * 4.549=4.655 \mathrm{~m}_{n}{ }^{3 *} \mathrm{~kg}^{-1} \quad \text { (from equation 8) } \\
& V_{\mathrm{Ar}}=0.0092 * 4.655=0.0428 m_{n}{ }^{3 *} \mathrm{~kg}^{-1} \quad \text { (from equation 5) } \\
& V_{\mathrm{H} 2 \mathrm{O}}=4.655-4.549=0.106 m_{n}{ }^{3 *} \mathrm{~kg}^{-1} \quad \text { (from equation 7) } \\
& V_{\text {H2O.vs }}=44.82 / 4.032 * 0.0577+22.41 / 18.016 * 0.0687+0.106=0.832 m_{n}{ }^{3 *} \mathrm{~kg}^{-1} \text { (from } \\
& \text { equation 6) } \\
& V_{\mathrm{sps}}=0.833+1.048 * 10^{-3}+3.552+0.043=4.429 \mathrm{~m}_{n}{ }^{3} \mathrm{~kg}^{-1} \quad \text { (from equation 4) } \\
& V_{s p v}=4.429+0.832=5.261 \mathrm{~m}_{n}{ }^{3 *} \mathrm{~kg}^{-1} \quad \text { (from equation 3) } \\
& V_{\mathrm{spnv}}=5.261+(1.5-1) * 4.655=7.791 \mathbf{m}^{3} * \mathbf{k g}^{-1} \quad \text { (from equation 2) }
\end{aligned}
$$

3.2.2 Calculation of the actual volume of wet flue gas for $100 \%$ wood pellets

$$
\begin{aligned}
& x_{v p}=1+70 / 100 * 3165 /(98050-70 / 100 * 3165)=1.023 m_{n}{ }^{3 *} k^{-1} \quad \text { (from equation 9) } \\
& V_{\mathrm{vZv}}=1.023 * 4.633=4.740 \mathrm{~m}_{n}{ }^{3 *} \mathrm{~kg}^{-1} \quad \text { (from equation 8) } \\
& V_{\mathrm{Ar}}=0.0092 * 4.740=0.044 \mathrm{~m}_{n}{ }^{3} \mathrm{~kg}^{-1} \quad \text { (from equation 5) } \\
& V_{\mathrm{H} 2 \mathrm{O}}=4.740-4.633=0.107 m_{n}{ }^{3 *} \mathrm{~kg}^{-1} \quad \text { (from equation 7) } \\
& V_{H 2 O . v s}=44.82 / 4.032 * 0.0631+22.41 / 18.016 * 0.0386+0.107=0.856 m_{n}{ }^{3 *} \mathrm{~kg}^{-1} \\
& V_{\mathrm{sps}}=0.910+9.785 * 10^{-5}+3.616+0.044=4.570 \mathrm{~m}_{n}{ }^{3} \mathrm{~kg}^{-1} \quad \text { (from equation 4) } \\
& V_{s p v}=4.570+0.856=5.426 m_{n}{ }^{3 *} k^{-1} \quad \text { (from equation 3) } \\
& V_{\mathrm{spnv}}=5.4261+(1.5-1) * 4.740=7.791 \mathbf{m}^{3}{ }^{3} \mathbf{k g}^{-1} \quad \text { (from equation 2) }
\end{aligned}
$$

\subsection{Determination of the amount of $\mathrm{CO}_{2}$ in the flue gas}

In the analytical model, we consider the amount of $\mathrm{CO}_{2}$ produced dependent only on the amount of $\mathrm{C}$ in the fuel. This equation is intended for the calculation of $\mathrm{CO}_{2}$ - perfect combustion. Conversely, in the case of incomplete combustion, the same relationship would determine the amount of $\mathrm{CO}$ generated, because the combustion of the combustible would not occur completely.

$$
V_{\mathrm{CO} 2}=22.41 * C^{r} / 12.011\left(m_{n}{ }^{3 *} \mathrm{~kg}^{-1}\right)
$$

Determination of the amount of CO for $100 \%$ straw pellets (from equation 10):

$$
V_{\mathrm{CO} 2 . \mathrm{s}}=22.41 * 0.4464 / 12.011=\mathbf{0 . 8 3 3} \boldsymbol{m}_{\boldsymbol{n}}{ }^{3 *} \boldsymbol{k g}^{-1}
$$

Determination of the amount of CO for $100 \%$ wood pellets (from equation 10):

$$
V_{\mathrm{CO} 2 . \mathrm{d}}=22.41 * 0.4878 / 12.011=\mathbf{0 . 9 1 0} \boldsymbol{m}_{\boldsymbol{n}}{ }^{3 *} \mathbf{k g}^{-1}
$$




\subsection{Determination of the amount of $\mathrm{SO}_{2}$ in the flue gas}

Similar to the calculation of $\mathrm{CO}$, the amount of generated $\mathrm{SO}_{2}$ emissions was determined through an analytical relationship:

$$
V_{\mathrm{SO} 2}=22.41 * \mathrm{~S}^{r} / 32.065\left(\mathrm{~m}_{n}{ }^{3 *} \mathrm{~kg}^{-1}\right)
$$

For $100 \%$ straw pellets, the total amount of $\mathrm{SO}_{2}$ (from equation 11) is:

$$
V_{\mathrm{SO} 2 . \mathrm{s}}=22.41 * 0.0015 / 32.065=1.048 * 10^{-3} \mathbf{m}_{\boldsymbol{n}}{ }^{3 *} \mathbf{k g}^{-1}
$$

For $100 \%$ wood pellets, the total amount of $\mathrm{SO}_{2}$ (from equation 11) is:

$$
V_{\mathrm{SO} 2 . \mathrm{d}}=22.41 * 0.00014 / 32.065=\mathbf{9 . 7 8 5} * 10^{-5} \mathbf{m}_{\boldsymbol{n}}{ }^{3 *} \mathbf{k g}^{-1}
$$

\subsection{Determination of the amount of $\mathrm{N}_{2}$ in the flue gas}

The calculation of the amount of $\mathrm{N}_{2}$ is based on the stoichiometric amount of dry air, i.e. of air which is introduced into the combustion chamber, it being assumed that all the oxygen will be used for the perfect combustion of the fuel. Another option is to determine the min. the amount of combustion air using the calorific value of the fuel, but this calculation is less accurate [4].

The determination of $\mathrm{N}_{2}$ is determined by the nitrogen supplied in the fuel and the nitrogen supplied in the combustion air:

$$
V_{\text {min.N2 }}=22.41 / 28.01 * N^{r}+0.7808 * V_{v z s . s}\left(m_{n}{ }^{3} * \mathrm{~kg}^{-1}\right)
$$

The calculation of the stoichiometric amount of dry air is based on the proportion of the stoichiometric amount of oxygen, with approximately $21 \%$ nitrogen in the dry air.

$$
V_{\mathrm{vzs}}=V_{\min .02} / 0.21\left(m_{n}{ }^{3} * \mathrm{~kg}^{-1}\right)
$$

With $V_{\min , \mathrm{O} 2}$ is calculated as:

$$
V_{\min .02}=22.41 *\left(C^{r} / 12.01 * H^{r} / 4.03+S^{r} / 32.06+N^{r} / 28.01-O^{r} / 32\left(m_{n}^{3} * k^{-1}\right)\right.
$$

Determination of the stoichiometric amount of oxygen for $100 \%$ straw pellets (from equation 12.1.1):

$$
\begin{array}{r}
V_{\min .02 . s}=22.41 *(0.4464 / 12.01 * 0.0577 / 4.03+0.0015 / 32.06+0.0426 / 28.01-0.3335 / 32= \\
=0.955 \mathrm{~m}_{n}{ }^{3} \mathrm{~kg}^{-1}
\end{array}
$$

Determination of the stoichiometric amount of dry air for $100 \%$ straw pellets (from equation 12.1):

$$
V_{\text {vzs.s }}=0.955 / 0.21=4.549 m_{n}{ }^{3 *} k^{-1}
$$

Determination of $\mathrm{N}_{2}$ in the flue gas for $100 \%$ straw pellets (from equation 12):

$$
V_{\min . \mathrm{N} 2}=22.41 / 28.01 * 0.0426+0.7808 * 4.549=3.552 \boldsymbol{m}_{\boldsymbol{n}}{ }^{3 *} \mathbf{k g}^{-1}
$$

Determination of the stoichiometric amount of oxygen for $100 \%$ wood pellets (from equation 12.1.1):

$$
\begin{array}{r}
V_{\min .02 . \mathrm{d}}=22.41 *(0.4878 / 12.01 * 0.0631 / 4.03+0.00014 / 32.06+0.0013 / 28.01-0.4132 / 32= \\
=0.973 \mathrm{~m}_{n}{ }^{3} \mathrm{~kg}^{-1}
\end{array}
$$


Determination of the stoichiometric amount of dry air for $100 \%$ wood pellets (from equation 12.1):

$$
V_{\text {vzs.d }}=0.973 / 0.21=4.633 m_{n}{ }^{3 *} \mathrm{~kg}^{-1}
$$

Determination of $\mathrm{N}_{2}$ in the flue gas for $100 \%$ wood pellets (from equation 12):

$$
V_{\text {min.N2 }}=22.41 / 28.01 * 0.0013+0.7808 * 4.633=3.616 \boldsymbol{m}_{\boldsymbol{n}}{ }^{3} \boldsymbol{k g}^{-1}
$$

\subsection{Comparison of gaseous emission values}

The values calculated using the analytical model would not necessarily correspond to reality due to differences in units. If the emission parameters were recorded in ppm, it would be necessary to convert the data to the same units to compare the model with the experimental data.

The production of emissions in the analytical model is in standard units $\mathrm{m}_{\mathrm{n}}{ }^{3 *} \mathrm{~kg}^{-1}$, the measured ppm values must be converted into standard units so that they can be compared with each other.

The conversion can be performed using equation 13 .

$$
Y=X^{*} M^{*} T * p /(22.41 * 273.15 * 101325)\left(m{ }^{*} m^{-3}\right)
$$

where:

$Y$ expresses the calculated emission production $\left[\mathrm{mg}^{*} \mathrm{~m}^{-3}\right]$,

$X$ is measured actual emission production [ppm],

$M$ indicates molar mass $\left[\mathrm{g}^{*} \mathrm{~mol}^{-1}\right]$,

22.41 is a constant - a value for a normal molar volume $\left[\mathrm{dm}^{3 *} \mathrm{~mol}^{-1}\right]$,

$T$ is the (mean) thermodynamic temperature $[\mathrm{K}]$,

$p$ indicates the actual pressure $[\mathrm{Pa}]$.

However, in order to determine the normalized value, it is necessary to make a recalculation and include in the calculation the normalized oxygen concentration $\left(\mathrm{O}_{2 \text { standard. }}\right)$ In the flue gas, while its value from the central heat source is $10 \%$. Subsequently, the emission production value is recalculated based on the oxygen content of the flue gas.

$$
Y_{(10 \% .02)}=Y^{*}\left(21-O_{2 . s t a n d a r d .} /\left(21-O_{2 . a v g .}\right)\left(m g^{*} m_{n}{ }^{-3}\right)\right.
$$

where:

$Y_{(10 \%, 02)}$ gives the normalized value of the emission concentration $\left[\mathrm{mg} \cdot \mathrm{m}^{-3}\right]$,

$Y$ is the calculated emission production according to equation $13\left[\mathrm{mg} \cdot \mathrm{m}^{-3}\right]$,

$\mathrm{O}_{2, \text { standard. }}$ is the normalized oxygen concentration in the flue gas [\%],

$\mathrm{O}_{2, \text { avg }}$ indicates the average value of the oxygen content in the flue gas in [\%].

The inverse of this quantity indicates the amount of measured emissions in the same units as the analytical model.

$$
V_{\mathrm{x}}=1 /\left(Y_{(10 \% .02) . \mathrm{x}} * 10^{-6}\right)\left(m_{n}{ }^{3 *} \mathrm{~kg}^{-1}\right)
$$




\section{Conclusion}

Based on a simple analytical model, it is possible to predict selected parameters of the combustion process. These parameters can provide a basic description of combustion, while the usability of such values lies in the possibility of correct setting of the combustion equipment as well as the adoption of appropriate measures for efficient and quality combustion.

Such a calculation also makes it possible to determine the approximate level of the emission load.

This research was funded by VEGA No. 1/0479/19 "Influence of combustion conditions on production of solid pollutants in small heat sources" and KEGA No. 038ŽU-4/2019" Piping systems in heat supply"

\section{References}

1. P. Durcansky, J. Jandacka, A. Kapjor, Determination of Initial Conditions for Heat Exchanger Placed in Furnace by Burning Pellets, AEaNMiFMaE (2014)

2. P. Durcansky, R. Lenhard, J. Jandacka, Comparison of mathematical models for heat exchanger of unconventional chp units, Acta Polytechnica, 55, 4 (2015)

3. Wageningen University and Research. 2016. LECO CN 628 Dumas analyser [online]. [Accessed 28-09-2020]. https://www.wur.nl/en/product/LECO-CN-628-Dumasanalyser-.htm

4. J. Jandačka, J. Mičieta, M. Holubčík., R. Nosek, Inovácie na zefektívnenie procesu spal'ovania biomasy. Žilina : EDIS - vydavatel'ské centrum ŽU, 265

5. V. Černý, a kol., Parní kotle, SNTL, Praha (1983) 